\title{
Les acides biliaires pourraient-ils être utiles dans le traitement du SIDA ?
}

Les acides biliaires n'ont pas fini de nous surprendre. Il y a 16 ans, on démontrait la possibilité de dissoudre des calculs vésiculaires cholestéroliques par l'un d'entre eux : l'acide chénodésoxycholique. Trois ans plus tard, un résultat similaire était observé avec l'acide ursodésoxycholique. Plus récemment, l'acide ursodésoxycholique se révélait très prometteur dans le traitement de la cirrhose biliaire primitive et plusieurs études contrôlées sont en cours pour tenter d'en confirmer l'efficacité et d'en préciser les indications, qui pourraient s'étendre à d'autres cholestases chroniques. Et voici qu'un groupe anglais vient de rapporter, in vitro, une étonnante propriété des acides biliaires: celle d'inactiver le virus HIV-l (le virus du SIDA) et de détruire les cellules infectées par ce virus.

La base de cette étonnante découverte est la suivante. Le virus HIV-l est un virus muni d'une enveloppe, comme tous les rétrovirus connus. L'enveloppe, qui est synthétisée par la cellule infectée à partir des informations données par le génome du virus, est très sensible aux détergents, aux solvants des lipides, et particulièrement aux acides biliaires. (On sait, par analogie, la propriété qu'a l'acide désoxycholique de dissoudre les membranes cellulaires.) Cette propriété ne serait qu'une curiosité de laboratoire si elle ne permettait déjà d'expliquer certaines observations in vivo: par exemple, les virus enveloppés ne sont habituellement pas infectants par voie orale, tandis que les entérovirus (qui ne possèdent pas d'enveloppe) le sont.

Les auteurs ont donc étudié les propriétés d'un mélange d'acides biliaires (acide cholique $60 \%$, acide désoxycholique $40 \%$ ) sur quatre lignées cellulaires infectées par le virus, les cellules non infectées servant de témoins. Après quatre jours d'infection, les cellules ont été exposées aux acides biliaires à des concentrations de 50 à $300 \mu \mathrm{g} / \mathrm{ml}$ pendant six heures ou sept jours. Le virus HIV-l a ensuite été recherché dans les cellules et dans le milieu de culture séparé par centrifuģation. Les cellules non infectées furent tuées seulement à des concentrations supérieures à $250 \mu \mathrm{g} / \mathrm{ml}$. Exposées pendant six heures aux acides biliaires, elles virent leur croissance cesser pendant trois à cinq jours, puis reprendre. En revanche, les cellules infectées par le virus HIV-1, exposées aux mêmes concentrations, moururent dans tous les cas sans jamais reprendre leur croissance. La multiplication du virus a été complètement inhibée par les acides biliaires: aucun marqueur du virus dans les cellules ni dans le surnageant n'a été détecté dans les cultures traitées par les acides biliaires pendant des durées allant jusqu'à 30 jours.

Des résultats similaires ont été observés avec un autre stéroïde ayant des propriétés physico-chimiques voisines de celles des acides biliaires: l'acide fusidique. De façon très remarquable, l'état clinique d'un malade atteint de SIDA traité par ce produit (qui est un antibiotique) en raison d'une infection opportuniste tuberculeuse s'est considérablement amélioré.

Ces observations extrêmement intéressantes indiquent une suppression complète de la multiplication du virus HIV-I en présence des acides biliaires aux concentrations utilisées, et une destruction des cellules infectées. A l'inverse, les cellules non infectées survivent et reprennent leur multiplication en culture. De même, les cellules infectées se multiplient dans les mêmes conditions en l'absence d'acides biliaires. Cette propriété pourrait-elle être utilisée en thérapeutique? D'ores et déjà elle pourrait expliquer les constatations épidémiologiques et l'absence d'infectiosité par voie orale. Une limitation importante à l'utilisation thérapeutique des acides biliaires dans le SIDA est leur faible biodisponibilité systémique lorsqu'ils sont administrés par voie orale. Ils sont, en effet, absorbés par l'intestin, très efficacement captés par le foie, sécrétés dans la bile et réabsorbés par l'intestin : ils sont donc, en pratique, «confinés » à la circulation entéro-hépatique. Il faudrait imaginer une administration parentérale à doses élevées, ou encore d'autres voies comme les aérosols, la voie perlinguale ou la voie rectale. On peut aussi concevoir des analogues non captés par le foie et ayant donc une plus grande biodisponibilité systémique. La toxicité générale, même à fortes concentrations, serait probablement assez faible, puisque des concentrations similaires dans la circulation générale sont observées chez certains malades ayant une cholestase chronique pendant plusieurs années.

Ces résultats très passionnants justifient probablement des études cliniques à la recherche d'un effet des acides biliaires sur le virus du SIDA chez l'homme.

S. E.

Lloyd G, Atkinson T, Sutton PM. Effect of bile salts and of fusidic acid on HIV-l infection of cultured cells. Lancet 1988; 1 : 141821. 